\title{
As redes para além dos rios: urbanização e desequilíbrios na Amazônia brasileira
}

\author{
Douglas Sathler \\ Fundação João Pinheiro (FJP/MG) \\ Roberto L. Monte-Mór \\ Professor do CEDEPLAR/UFMG \\ José Alberto Magno de Carvalho \\ Professor do CEDEPLAR/UFMG e Diretor da FACE/UFMG
}

\section{Palauras-chave \\ redes urbanas, Amazônia, desequilíbrios.}

Classificação JEL R00.

\author{
Key words \\ urban networks, Amazonia, \\ imbalances.
}

JEL Classification R00.

\section{Resumo}

Nas últimas décadas, as redes urbanas que se estendem sobre a Amazônia Legal têm evoluído com o surgimento de cidades médias e com a multiplicação de pequenas aglomerações urbanas, que seguem os traçados das principais rodovias e rios da região. Apesar disso, as redes da Amazônia Legal apresentam diversos aspectos que devem ser estudados sem "euforia", diante de uma série de peculiaridades que merecem ser exploradas com maior profundidade. Mesmo que tenha sido estruturada uma hierarquia urbana aparentemente similar à das demais regiões do país, com centros regionais e locais claramente distinguíveis, os diversos níveis hierárquicos urbanos apresentam dinâmicas demográficas, socioeconômicas e espaciais distintas. A situação de fragilidade das redes urbanas amazônicas está relacionada à criação de impedimentos para os fluxos de pessoas, mercadorias e serviços, cabendo destacar: a) as grandes distâncias que separam as capitais das demais cidades e vilas; b) a carência de infra-estrutura nos setores de transporte e comunicação em grandes porções do território amazônico; c) a grande proporção de população desprovida de recursos materiais e educacionais decisivos no que tange a sua participação ativa nos diversos tipos de fluxos.

\section{Abstract}

In recent decades, the Amazonian urban networks have been developing with the appearance of medium-sized cities and the multiplication and small urban agglomerations along the main regional roads and rivers. However, Amazonian urban networks have several characteristics that should be studied without "euphoria", because of some peculiarities that deserve to be explored in greater depth. Even though there is an urban bierarchy that seems to be similar to the other regions of the country, with clearly distinguishable regional and local centers, the various urban hierarchical levels have different demographic, spatial and socioeconomic dynamics. The fragility of the Amazonian urban networks is related to the creation of barriers for the flows of people, goods and services, like: a) the great distances that separate the capital cities from the other towns and hamlets; b) the lack of transport and communication infrastructure in large areas of the Amazon territory; c) the large proportion of the population without material and educational resources needed for them to actively participate in the various kinds of flows. 


\section{1_Introdução}

As redes urbanas que se estendem sobre a Amazônia Legal têm evoluído com o surgimento de cidades de porte intermediário e com a multiplicação de pequenos centros urbanos, que seguem os traçados das principais rodovias e dos rios da região. Deve-se ressaltar que, há poucas décadas, essa extensa porção do território brasileiro era caracterizada por um pequeno número de cidades, dispersas pela floresta, interconectadas por canais de drenagem, vias únicas de integração daquelas localidades. A população exercia atividades com características distantes daquelas praticadas nos centros urbanos, e a economia era essencialmente voltada para as ocupações ligadas aos rios e à floresta.

A urbanização dos Estados amazônicos atravessou duas fases historicamente distintas: na primeira, anterior aos anos 1960, esse processo nascia e se desenvolvia predominantemente pelos rios; já na segunda fase, a exploração mineral e os grandes projetos estimularam o crescimento urbano com o auxílio das rodovias após os anos 1960 (Souza, 2000).

Não obstante o significativo crescimento demográfico das capitais estaduais nas últimas décadas, a recente conformação de núcleos urbanos dotados de expressivos contingentes populacionais no interi- or da região lançou vários desafios relacionados com o equilíbrio no que tange à organização, à disposição e à interação das cidades na Amazônia Legal. Nesse contexto, deve-se ressaltar que essas transformações parecem romper com a enorme dificuldade de interiorização da ocupação em vastas regiões da Amazônia Legal.

Nas últimas décadas, foi deflagrada uma verdadeira explosão urbana nas proximidades das principais ligações rodoviárias da região, diante de movimentos migratórios de grande intensidade (Matos, 2005). As taxas de crescimento populacional foram superiores às médias nacionais, resultantes, sobretudo, dos intensos fluxos migratórios com origem nas regiões Nordeste e Sul.

Apesar disso, as redes da Amazônia Legal apresentam diversos aspectos que devem ser interpretados sem "euforia", diante de uma série de peculiaridades que merecem ser exploradas com mais profundidade. Apesar de haver sido estruturada, em algumas porções da Amazônia Legal, uma hierarquia urbana aparentemente similar à das demais regiões, com centros regionais e locais claramente distinguíveis, os diversos níveis hierárquicos urbanos apresentam dinâmicas demográficas, socioeconômicas e espaciais distintas daquelas estabelecidas para as redes de cidades do Centro-Sul do País. Nesse sentido, o presente estudo dialoga 
com as especificidades das redes de cidades da Amazônia Legal, buscando melhor entendimento do significado das transformações sócio-espaciais recentes.

\section{2_As "redes móveis" na era da informação}

As abordagens mais comuns acerca das dinâmicas das redes urbanas buscam levar em consideração questões importantes, tais como a diferenciação funcional das cidades, as relações entre tamanho demográfico e desenvolvimento, a hierarquia urbana e as relações entre cidade e região. A rede urbana é concebida como um conjunto de centros funcionalmente articulados e, nesse sentido, a intensificação da globalização em vastas áreas do mundo tem remodelado os padrões de hierarquia e de relacionamento entre as cidades.

O avanço da globalização tem papel fundamental na intensificação dos diversos tipos de fluxo. Esse processo, com forte viés econômico-espacial, é definido como a compressão do mundo e a intensificação de uma consciência global, o que alarga e aprofunda as relações sociais. Assim, eventos globais passam a moldar acontecimentos locais, e vice versa (Robertson, 1992; Soja, 2000).
Diante dessas intensas mudanças nas relações sociais, Santos (1994, p. 167) declara que vê

"o mundo constituido de fixos e de fluxos, por uma paisagem e relações sociais; como um conjunto de lugares onde o acontecer simultâneo dos diversos agentes supõe o uso diferenciado do tempo".

Neste sentido, o autor (1994, p. 167) ressalta que "o tempo é a base indispensável para o entendimento do espaço".

As definições conceituais de rede se enquadram em duas grandes matrizes: a que apenas considera sua realidade material e a que também leva em conta o dado social. A primeira se encaixa na definição de Curien (1988, p. 212), sendo a rede composta de "toda infraestrutura, permitindo o transporte da matéria, de energia ou de informação, e que se inscreve sobre um território [...]". Não obstante, Santos esclarece que

"a rede é também social e politica, pelas
pessoas, mensagens, valores que a freqüen-
tam. Sem isso, e a despeito da materiali-
dade com que se impõe aos nossos sentidos,
a rede é, na verdade, uma mera abstra-
ção" (Santos, 1997, p. 209).

As cidades são os nódulos dos sistemas de fluxos, que, por sua vez, dinamizam a rede urbana e estruturam o território. $\mathrm{Na}$ 
era das cidades industriais, as redes urbanas se organizavam a partir da influência primordial dos fluxos materiais. Com a revolução científica e informacional, os fluxos simbólicos se tornaram mais decisivos na definição das hierarquias urbanas e da capacidade de polarização de cada um de seus nódulos. Segundo Santos (1978, p. 87),

"convém lembrar que a economia mundial de nossos dias não é mais governada pelos que detêm as massas, isto é, os que produzem, mas pelos que se encontram em condiçôes de transformar essas massas em fluxos".

No que tange ao dinamismo e ao funcionamento das redes urbanas, a globalização exerce uma série de impactos, a saber:

a. intensifica os fluxos;

b. amplia o alcance das redes e dos diversos nós;

c. estimula a regionalização;

d. muda a direção dos fluxos com a possibilidade do aprofundamento das relações entre o local e o global sem a atuação de centros intermediários;

e. amplia a possibilidade de especialização funcional por parte das cidades;

f. atua na criação de áreas de exclusão.

A partir da revolução informacional, as cidades passaram a interagir com lugares cada vez mais distantes. A ampliação abrupta dos raios de influência das cidades que protagonizaram essas transformações econômicas e sócio-espaciais atuou na integração de redes que, até então, não se relacionavam ou se relacionavam com pouca intensidade.

Dessa forma, as décadas anteriores foram marcadas pelo aumento do alcance. Mesmo diante das extensas áreas de exclusão, o mundo parece ter ficado pequeno com o poder de alcance dos fluxos. Nesse ritmo de constantes inovações, outros paradigmas estão sendo quebrados nas porções mais desenvolvidas do globo, na atualidade. $\mathrm{O}$ alcance já não surpreende tanto diante das novas formas de flexibilidade e interatividade que surgiram e/ou se enraizaram após a virada do milênio.

De acordo com Santos (1994, p. 167), a rede urbana é definida por "fluxos de informação hierarquizados e fluxos de matéria que, nas áreas mais desenvolvidas, não são hierarquizantes". Apesar da evidente distinção, deve-se ter em mente que os fluxos de informações e matérias geralmente estão intimamente relacionados e não existem separadamente.

No que se refere aos fluxos de informações, esses são, cada vez mais, gerados por fontes desprendidas do mundo constituído de fixos. O mundo já está bem diferente daquele imaginado e pensado por 
Milton Santos e outros grandes teóricos das décadas anteriores. A flexibilidade das fontes que emanam e recebem informações atingiu níveis impressionantes.

Nos últimos anos, as ligações realizadas com o uso de telefone fixo têm sido proporcionalmente reduzidas com a invasão do celular, companheiro sempre presente que oferece uma mobilidade que mudou a rotina das pessoas. O correio tradicional e o fax foram, em grande medida, substituídos pelo e-mail, caixa postal eletrônica que acompanha as pessoas em qualquer lugar que haja conectividade. Os fluxos materiais também são impulsionados em um mundo em que se pode comprar e solicitar de tudo pela internet ou pelo telefone. Maior flexibilidade significa poder gerar ou absorver um fluxo, de qualquer natureza, de maneira mais imediata e livre, em qualquer lugar que a pessoa esteja.

De maneira mais recente, o aumento da interatividade tem causado impactos incríveis no dinamismo das redes mundiais. Um dos grandes agentes da interatividade, sem sombra de dúvida, é a internet, cada vez mais acessada e modernizada, criando um mundo de fluxos sem distâncias e direções, ou seja, para as pessoas, as coisas já não parecem vir de algum lugar, elas já estão o tempo todo na frente delas.
Como forma de exemplificar o aumento na interatividade, pode-se citar:

a. a eficiência das ferramentas de busca do Google;

b. o mundo em imagens do Google Earth;

c. o Google Maps;

d. o surgimento e a popularização do Skype, que permite a troca de informações entre pessoas de todas as partes do globo a custos muito mais baixos do que o sistema tradicional de telefonia;

e. a riqueza do banco de informações do Youtube;

f. a difusão de rádio e televisão via web;

g. a divulgação irrestrita de arquivos, vídeos e músicas MP3 na internet com ferramentas de busca sofisticadas, a exemplo dos sites de "torrent";

h. novos hardwares portáteis, como o HD portátil e o "pen drive";

i. a incorporação de novas ferramentas no aparelho celular que permitem o registro de fotos, vídeos, o acesso a dados bancários e à caixa de e-mails;

j. a criação de uma identidade digital através de sites de relacionamento do tipo Facebook e Orkut. 
Diante de todas essas inovações no universo das informações, a rede urbana ganha força com o papel central desempenhado pelas cidades e demais prolongamentos do tecido urbano na intermediação dos fluxos, embora esses tenham se rebelado contra os caminhos tradicionais.

$\mathrm{Na}$ esfera do indivíduo, o grande agente transformador, as redes possuem pontos que parecem mudar de lugar a todo o momento além de fluxos que não obedecem a caminhos rígidos, ou dão a impressão de fazer caminho algum, saindo e chegando instantaneamente, ou apenas "estando". Pessoas, empresas e cidades estimulam um sentimento de onipresença sem precedentes. Nessa perspectiva, as redes não são mais geométricas. Elas assumem formas visíveis e invisíveis impossíveis de ser definidas ou desenhadas. Assim, o mundo passa a conhecer não apenas as tradicionais redes dendríticas e complexas, contando agora com vastas regiões dotadas de redes móveis.

As ideias apresentadas por Castells, ao final do século, no seu livro sobre $A$ sociedade em rede, já traziam elementos que ajudam a justificar o nascimento das redes móveis em um plano conceitual, mesmo sem levar em consideração o surto de inovações após a vira da do milênio. Segundo o autor,

o desenvolvimento da comunicação eletrônica e dos sistemas de informação propicia uma recente dissociação entre proximidade espacial e o desempenho das funções rotineiras: trabalho, compras, entretenimento, assistência à saúde, educação, serviços públicos, governo e assim por diante. Por isso, os futurologistas freqüentemente predizem o fim da cidade, ou pelo menos das cidades como as conhecemos até agora, visto que estão destituidas de sua necessidade funcional (Castells, 1999, p. 419).

Alguns dos exemplos apontados por Castells (1999) para a década de 1990 parecem se destacar, cada vez mais, nos dias atuais, tais como:

a. a substituição do serviço em ambiente de trabalho pelo trabalho on-line, em casa, com o aumento do teletrabalho e das consultorias em resposta ao processo de terceirização;

b. o ensino a distância, oferecido, sobretudo, pelas universidades, também apresentou aumento durante a década de 1990;

c. apesar de seu caráter complementar, as atividades comerciais tradicionais, as compras via web e o telefone têm crescido no início dos anos 1990 e se tornaram um surto após a virada do milênio;

d. a supervisão por videoconferência de procedimentos cirúrgicos. 
Tudo isso vai ao encontro do aumento da mobilidade nos países desenvolvidos e, em menor medida, nos países em desenvolvimento.

Em alguns países em desenvolvimento, e particularmente no Brasil, em que pese a relativa restrição infraestrutural, principalmente nos sistemas de transporte, o sistema de comunicações vem se desenvolvendo de forma surpreendentemente intensa e disseminada. Em algumas regiões, a telefonia celular atinge proporções comparáveis a países desenvolvidos, e também o uso de computadores vem aumentando significativamente. Entretanto, em que pese essa transformação, a cobertura de serviços de comunicação e informacionais em níveis equivalentes aos países do centro exigirá ainda muito tempo e esforço, até porque, daqui em diante, os ganhos percentuais passam a ser mais lentos, com a incorporação de pequenos municípios, exigindo grandes investimentos para áreas de baixa densidade.

De acordo com os dados divulgados no site da Anatel, 63,6\% da população brasileira (cerca de 121 milhões de pessoas) possuía acesso pessoal ao celular em 2007, contra 20,3\% em 2002. Nesse mesmo período, o número de telefones públicos fixos caiu de 1.368.200 para 1.142.000 no País. A título de comparação, os dados do
"IBGE Países" para 2005 indicavam que 46,25\% dos brasileiros possuíam telefone celular, valor significativo, mas ainda inferior, proporcionalmente, a países como Argentina (57,41\%), Chile $(67,79 \%)$, Estados Unidos (71,50\%), África do Sul (71,60\%), Japão $(75,33 \%)$ e Rússia $(83,62 \%)$ no mesmo ano.

Já no que tange ao número de computadores pessoais a cada 100 habitantes, o Brasil (16,09\%) está à frente de outros países em desenvolvimento como a África do Sul (8,36\%), a Argentina (9,07\%), a Rússia $(12,13 \%)$ e o Chile (14,75\%). Apesar disso, os dados indicam que, em 2005, os valores desses países em desenvolvimento estavam muito distantes em relação ao que foi verificado para países como Estados Unidos (76,22\%) e Japão (67,45\%). Com relação ao percentual de pessoas que usavam internet em 2005, o Brasil (21\%), assim como outros países em desenvolvimento, como África do Sul (10,75\%), Argentina (17,78\%) e Chile $(28,93)$, ainda apresentavam valores bem abaixo daqueles encontrados para os Estados Unidos (66,33\%) e o Japão (66,59\%) nesse mesmo ano.

Neste contexto de transformações globais, as redes da Amazônia brasileira se inserem numa mistura de inserção e exclusão, de velocidade e atraso. A criação de espaços que interagem, coexistem ou se 
distanciam pode ser percebida nas diversas escalas de análise. No nível global, deve-se destacar a importância dos impactos gerados pelo processo de globalização, não apenas na economia e nas finanças, mas também na redefinição do papel do Estado, na natureza e no aumento da velocidade de transformação das atividades e dos territórios com o aperfeiçoamento das redes técnicas. Do ponto de vista regional e local, o acesso às redes também é dependente dos atributos do território, da potencialidade humana e das iniciativas políticas (Becker, 2001).

Mesmo que as distâncias para os diversos tipos de fluxo ainda continuem especialmente grandes na Amazônia brasileira, percebe-se que muitas das mais recentes inovações do mundo desenvolvido chegam, com simultaneidade, nas maiores cidades da região. Esse mix de avanço e atraso pode ser percebido muito fortemente nas maiores cidades amazônicas e, até mesmo, nas médias e nas pequenas cidades do interior da região.

Os próximos tópicos traçam um panorama do que tem sido o processo de urbanização da Amazônia Legal brasileira, com o objetivo de investigar melhor o real significado das relações entre as cidades da região.

\section{3_Urbanização e evolução das redes de cidades na Amazônia Legal}

A atual conformação das redes de cidades da Amazônia Legal foi produzida por um processo de urbanização distinto das demais regiões do Brasil, sendo enormemente influenciada pelas intervenções estatais que ocorreram a partir da década de 1960. O desenvolvimento da fronteira urbana, que pode ser entendida como a base logística para o projeto de rápida ocupação da região, muitas vezes se antecipando à expansão de várias frentes, foi impulsionado pelo incentivo a grandes empreendimentos e pela política de migração induzida e financiada pelo Estado. Novos núcleos foram criados, sobretudo em apoio a projetos de mineração, agropecuária e colonização (Becker, 1990).

A história conta que o surgimento e a proliferação das cidades comumente estão diretamente relacionados à criação de excedentes nas áreas rurais. Entretanto, deve ficar claro que, em alguns casos, a cidade pode nascer na frente do campo, como em grandes áreas na Amazônia em que as cidades servem como bases logísticas para a exploração dos recursos naturais e para a implementação de atividades agropecuárias. 
洒,

1 O ciclo da borracha conferiu dinamismo à Amazônia da década de 1870 até 1920 , quando praticamente foi extinto pela concorrência com a produção organizada pelos ingleses na Malásia. Durante a II Guerra Mundial, face ao bloqueio da região asiática, a borracha experimentou rápida sobrevida na Amazônia.
Em boa parte dos casos, as cidades na Amazônia costumam responder ao que acontece em seus arredores. Nas áreas de mineração, desflorestamento e mesmo nas áreas tomadas pela agricultura mecanizada, a lógica urbana e industrial esteve sempre presente. Dessa maneira, assim como em outras partes do País, em vastas regiões da Amazônia Legal, a urbanização que ultrapassa as barreiras das cidades, favorecida pelo desenvolvimento do meio técnico científico e informacional e pelo apoio da forte presença das relações de produção urbanoindustriais, pode ser compreendida com o auxílio do conceito de urbanização extensiva. Esse termo se refere ao avanço do tecido urbano que extrapola os limites das cidades com a geração de outras centralidades urbanas, expressando um amplo processo econômico-espacial (Monte-Mór, 1994).

No que se refere ao processo de formação e de desenvolvimento das cidades na Amazônia Legal, pode-se traçar algumas tipologias bastante úteis. Na maior parte dos casos, essas tipologias apresentam um ponto em comum: as atividades econômicas que promoveram o surgimento das cidades amazônicas estiveram direcionadas para o mercado externo. Assim, as cidades da borracha, a cidade industrial (Manaus), as cidades da grande empresa mineradora, as cidades do garimpo (des) organizado e as cidades de apoio a projetos agroindustriais aparecem como importantes do ponto de vista do crescimento urbano na Amazônia Legal. De maneira diferenciada, todavia, aparecem os diversos centros locais, que eventualmente se transformaram em centros de porte intermediário, mas que foram gerados a partir das necessidades e demandas colocadas por uma economia agropecuária de pequeno porte ligada aos vários projetos de colonização, oficiais e privados, que foram implantados por toda a Fronteira Amazônica a partir dos anos setenta.

As cidades que surgiram e se desenvolveram durante o ciclo da borracha, ${ }^{1}$ responsável pelo grande impulso às cidades de Manaus e Belém, tiveram que encontrar um modo alternativo de sobrevivência com o fim dessa atividade econômica. No caso de Manaus, a criação da Zona Franca atraiu significativos investimentos que construíram o que hoje é o maior PIB municipal da Amazônia brasileira (cerca de 20\% do PIB de toda a Amazônia Legal, em 2005).

Já em Belém, a indústria tradicional, o extrativismo, o turismo e o comércio e serviços são atualmente responsáveis pela sustentação econômica dessa grande cidade e dos demais municípios que formam seu $c o$ re metropolitano. Além disso, outras cidades de hierarquia inferior, posicionadas no 
eixo do rio Amazonas, também se beneficiaram com o ciclo da borracha, a exemplo de Santarém, hoje considerada importante entreposto comercial diante de sua posição estratégica, situação que se pode tornar muito mais favorável se o asfaltamento da rodovia federal BR-163 se concretizar. ${ }^{2}$

Nas cidades mineradoras, após o início da exploração das jazidas, o vertiginoso crescimento populacional com o surgimento de uma série de incentivos econômicos desafia os formuladores e os gestores de políticas públicas, que nem sempre conseguem se organizar em prol do atendimento satisfatório das novas demandas sociais e econômicas. Nesse sentido, em vários momentos, a insuficiência, ou mesmo a ausência, de planejamento urbano favoreceu o surgimento de problemas crônicos em várias cidades amazônicas, sobretudo nos campos de infraestrutura e serviços.

Ademais, se por um lado a instalação de uma grande mineradora em uma região pode criar uma série de oportunidades econômicas, a exemplo do que hoje acontece na cidade de Parauapebas, que usufrui dos royalties da Vale, percebe-se que o esgotamento do minério pode condenar ao fracasso toda uma cadeia de serviços com alto nível de dependência dessa atividade. Além disso, a concentração local de capital em atividade dinâmica inserida no mercado glo- balizado atrai enorme quantidade de pessoas que não conseguem inclusão na economia exportadora local e encontram apenas condições precárias para sobrevivência econômica e reprodução social.

De forma geral, nas cidades sob a atuação das grandes empresas do setor, os projetos mineradores não preveem estratégias de sustentabilidade econômica para os municípios que lhes dão suporte após o processo de desativação das minas com o esgotamento dos recursos. Nesse caso, as Administrações Municipais podem não ter eficiência no que tange ao aproveitamento das vantagens econômicas diretas e indiretas, oriundas do período de dinamismo gerado pelas atividades mineradoras. A falta de planejamento acaba por condenar a cidade à estagnação, com o fim dos royalties $\mathrm{e}$ dos demais impulsos econômicos gerados pela mineração. Assim, a formulação de estratégias que busquem a reconfiguração das bases estruturais socioeconômicas das regiões mais impactadas, com o diagnóstico das potencialidades e das oportunidades no processo de reestruturação produtiva, aparece como indispensável.

Em situação mais desfavorável, as cidades de apoio ao garimpo (des)organizado parecem estar mais susceptíveis às forças de estagnação do período pós-mineração, reflexo da falta de planejamento anterior às
A rodovia BR-163, ligando Cuiabá a Santarém, poderá se tornar importante porta de saída para a exportação da soja brasileira. Em acordo com o que foi discutido na IIIa Conferência Nacional do Meio Ambiente - mudanças climáticas, as vantagens comparativas da construção de uma ferrovia face à rodovia são múltiplas, e não exclusivamente de ordem econômica, mas também ambiental, uma vez que as rodovias causam impacto muito maior sobre a floresta, a exemplo do já ocorrido no grande "arco rodoviário" que conformou a fronteira amazônica. 


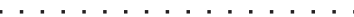

3 O estoque populacional relativamente pequeno da Amazônia Legal no início desse período deve ser considerado na interpretação das altas TCG entre 1970-1980. altas taxas de crescimento demográfico que normalmente exibem nos períodos de auge da atividade. Aqui, pode-se citar o exemplo de Marabá, cidade que obteve dinamismo com a exploração das minas da Serra Pelada, sobretudo durante a década de 1980, e que experimentou alguns anos de depressão econômica até que as atividades siderúrgicas constituíssem uma alternativa viável. Por outro lado, Itaituba, que não conta com as vantagens advindas do posicionamento estratégico de Marabá, vivencia uma crise de identidade econômica aguda com o fim da atividade garimpeira.

No caso das cidades que servem de apoio aos grandes projetos agroindustriais, a alta concentração de renda e a falta de recursos municipais, uma vez que não existem royalties agroindustriais, são características comuns a essas ilhas de pobreza, cercadas por um oceano que conta com o que há de mais moderno nesse setor, a exemplo do que ocorre em Balsas (MA).

Entre as cidades que surgiram como lugares centrais de apoio à atividade agropecuária de base familiar, nos vários projetos de colonização públicos e privados implantados, ao longo das principais rodovias federais, algumas se desenvolveram de forma surpreendente, transformandose em centros comerciais e de serviços importantes em sua área de influência, por vezes superando a casa dos 50.000 habitantes, a exemplo de Ji-Paraná, em Rondônia. A demanda por serviços urbanos e sociais na região fez, em alguns casos, que cidades pretendidas para funções centrais de âmbito local passassem a desempenhar papel polarizador microrregional em suas esferas de atuação.

Ao longo das últimas décadas, o aumento do dinamismo das redes urbanas nas proximidades das principais rodovias amazônicas se refletiu nas altas Taxas de Crescimento Geométrico (TCG) para a região. De acordo com os Censos Demográficos, a TCG da população da Amazônia Legal entre 1970 e 1980 (4,43\% a.a.) esteve bem acima da média nacional (2,5\% a.a.). ${ }^{3}$ Entre 1980 e 1991, o valor da TCG nessa região se reduziu para 3,51\% a.a., caindo ainda mais entre $1991-2000$ (2,48\% a.a.). A partir dos dados da contagem populacional de 2007, realizada pelo IBGE, e das estimativas realizadas para os médios e grandes municípios não cobertos pela pesquisa, percebe-se que a TCG continuou a decrescer, atingindo 1,64\% a.a. entre 2000-2007, mas permanecendo acima da média nacional no mesmo período (1,15\% a.a.).

Com relação à evolução do crescimento das cidades, a Tabela 1 apresenta a distribuição dos municípios por classes de tamanho populacional, entre 1970 e 2007. 
Tabela 1 Distribuição dos Municípios da Amazônia Legal por classes de tamanho populacional entre 1970 e 2007

\begin{tabular}{|c|c|c|c|c|c|c|c|c|c|c|}
\hline \multirow{2}{*}{$\mathbf{N}^{\circ}$ de habitantes } & \multicolumn{2}{|c|}{1970} & \multicolumn{2}{|c|}{1980} & \multicolumn{2}{|c|}{1991} & \multicolumn{2}{|c|}{2000} & \multicolumn{2}{|c|}{2007} \\
\hline & n & $\%$ & n & $\%$ & $\mathbf{n}$ & $\%$ & n & $\%$ & n & $\%$ \\
\hline menos de 20.000 & 239 & 71,99 & 221 & 60,38 & 303 & 59,88 & 530 & 69,65 & 516 & 67,81 \\
\hline 20.000 a 50.000 & 73 & 21,99 & 102 & 27,87 & 142 & 28,06 & 167 & 21,94 & 170 & 22,34 \\
\hline 50.000 a 100.000 & 15 & 4,52 & 31 & 8,47 & 43 & 8,50 & 43 & 5,65 & 49 & 6,44 \\
\hline $100.000 \mathrm{a} 1.000 .000$ & 5 & 1,51 & 12 & 3,28 & 16 & 3,16 & 19 & 2,50 & 24 & 3,15 \\
\hline mais de 1.000 .000 & 0 & 0,00 & 0 & 0,00 & 2 & 0,40 & 2 & 0,26 & 2 & 0,26 \\
\hline Total & 332 & 100 & 366 & 100 & 506 & 100 & 761 & 100 & 761 & 100 \\
\hline
\end{tabular}

Fonte: IBGE. Censos demográficos 1970 a 2000. IBGE (2008a).

Nota: O número total de municípios varia durante os anos analisados com as emancipações.

Em 1970, havia apenas 20 municípios com população superior a 50 mil habitantes, dos quais apenas cinco possuíam mais de 100 mil habitantes, enquanto 239 (72\% dos municípios da região) apresentavam população inferior a 20 mil. Já em 1980, percebe-se aumento no grau de complexidade das redes urbanas da Amazônia, que contava com a presença de 12 municípios com mais de 100 mil habitantes e 31 municípios com população entre 50 e 100 mil.

Em 1991, já existiam pouco mais de 500 municípios na Amazônia Legal, dos quais 16 tinham entre 100 mil e 1 milhão de habitantes. Vale destacar que, naquele ano, Belém e Manaus já superavam o limiar de 1 milhão de pessoas e que, mesmo com um incremento de 140 novas unidades territoriais via emancipação entre 1980-1991, a participação dos municípios de maior população no total da região seguiu aumentando; aqueles acima de 50 mil representavam mais de $12 \%$ do total de municípios em 1991.

A década de 1990 foi marcada, em todo o Brasil, por uma explosão de pequenos municípios resultantes das emancipações ocorridas, sobretudo nos anos de 1993 e 1997. Nesse período, surgiram 255 novos municípios na Amazônia Legal. Como a maioria dessas novas localidades se emancipou com população inferior a 20 mil habitantes, a participação percentual dessa faixa aumentou em detrimento das demais, atingindo valores próximos aos de 1970 . Em contrapartida, o número de municípios com mais de 100 mil habitantes também aumentou de 18 para 21, entre os anos de 
4 A representação está de acordo com a malha municipal de cada ano em questão.

Nesse período, os dados de população para os municípios emancipados não estão agregados.
1991 e 2000. De acordo com os dados mais recentes da Tabela 1 , parece claro que as modificações se concentraram nas cidades de médio porte da Amazônia. O número de municípios com mais de 100.000 habitantes era de 19, em 2000, aumentando para 24, em 2007. Da mesma forma, os municípios com população entre 50.000 e 100.000 residentes aumentaram para 49 no último ano analisado, contra $43 \mathrm{em} 2000$.

Como forma de ampliar as possibilidades de interpretação dessa tabela, a distribuição espacial da evolução demográfica dos municípios amazônicos no mesmo período pode ser visualizada nas Figuras 1 e 2 do Anexo. ${ }^{4}$ Como pode ser observado, torna-se claro o impacto da malha viária para o desenvolvimento das aglomerações urbanas na região. A expansão urbana (e populacional) foi mais intensa sobretudo ao longo das rodovias que cortam as porções Sul, Sudoeste e Leste da região, além da ocupação que segue os contornos do rio Amazonas até Manaus. Entretanto, permanece vasta a região de baixa ocupação no Sudoeste do Pará e grande parte do Amazonas, além da parte superior do rio Amazonas, estendendo-se pelo Sul de Roraima até o Norte do Estado do Amapá.

As recentes transformações citadas neste tópico têm gerado interpretações que muitas vezes não são condizentes com a rea- lidade urbano-regional, apoiadas na falácia de que as cidades amazônicas já não estariam organizadas em um modelo simplificado de rede urbana, o qual teria sido rompido com a introdução de novas cidades médias e com o surto de crescimento de pequenos municípios na região. Entretanto, no caso das redes urbanas amazônicas, parece claro que não apresentam o mesmo nível de equilíbrio e complexidade encontrado nas regiões dinâmicas do Brasil, ou mesmo em outras regiões desenvolvidas do mundo. $\mathrm{Na}$ Amazônia, a integração econômico-espacial promovida pela globalização não foi suficiente para reduzir significativamente as distâncias entre as pequenas cidades e os demais níveis hierárquicos das redes urbanas, diante de uma série de atritos que reduzem ou inviabilizam diversos tipos de fluxo. Sendo assim, cabe explorar com mais profundidade as especificidades amazônicas nesse contexto de transformações.

\section{4_Especificidades das redes urbanas da Amazônia Legal}

Diante das recentes transformações na organização e na estruturação das cidades no território amazônico, à primeira vista pode-se inferir que existe uma rede urbana dinâmica, com várias cidades médias e centros locais com forte poder de 
interação. Isso porque, como mostra a Figura 2 do Anexo, as cidades amazônicas parecem estar organizadas de forma similar à atual conformação dos centros urbanos na região Centro-Sul do País. Entretanto, um olhar mais atento, apoiado em outros argumentos, leva-nos a questionar essa interpretação, cabendo destacar aquele que parece ser o argumento mais imediato: as escalas espaciais da região amazônica são bastante distintas.

A situação de fragilidade das redes urbanas amazônicas está relacionada à criação de uma série de impedimentos para os fluxos de pessoas, mercadorias e serviços, cabendo destacar:

a. as grandes distâncias que separam as capitais das demais cidades e vilas;

b. a carência de infraestrutura nos setores de transporte e comunicação em grandes porções do território amazônico;

c. a grande proporção de população desprovida de recursos materiais e educacionais decisivos para sua participação ativa nos diversos tipos de fluxo.

$\mathrm{Na}$ Amazônia, as grandes distâncias entre centros locais, cidades de porte médio e as maiores cidades da região criam limitações nos fluxos de bens, pessoas e ser- viços entre os diversos níveis hierárquicos urbanos. Ademais, a própria distribuição dos centros urbanos no território amazônico se dá de maneira bastante desigual, com nítida concentração de cidades nas intermediações de um "arco rodoviário" formado pelas grandes rodovias federais que envolvem e/ou cortam a região sem, no entanto, apresentar a mesma intensidade de penetração e articulação interna com os espaços regionais. Isso cria uma dificuldade evidente no que diz respeito aos fluxos entre as cidades pertencentes ao "arco" e os demais centros no interior do território.

Além disso, parece evidente a carência de infraestrutura nos setores de comunicação e transportes, em grandes porções do território amazônico. Os baixos investimentos nesses setores se refletem na criação de um ambiente contrário ao que seria necessário para a aceleração dos fluxos no interior da região. Mesmo com a presença de alguns investimentos relativamente grandes na atual carteira de distribuição de recursos governamentais, percebe-se que alguns desses, como no caso da construção de grandes hidroelétricas, priorizam a geração de riqueza e de bens que não vão ser aproveitados em toda sua magnitude dentro da região.

Para compreender melhor a dinâmica das redes amazônicas, não se pode 
$\ldots \ldots \ldots$ (2008, p. 3), "as redes são diferenciadas em termos de tamanho, organização e complexidade e apresentam interpenetrações devido à ocorrência de vinculação de mais de um centro, resultando em dupla ou tripla inserção na rede". olhar apenas para os aspectos externos aos centros urbanos. É fundamental lançar luz sobre as características internas aos centros, exercício indispensável para compreender a intensidade e o direcionamento dos fluxos. Ao se aprender a olhar a cidade por dentro, com o objetivo de conhecer melhor suas especificidades intraurbanas, torna-se mais fácil entender a forma como as cidades interagem e se integram.

Nesse sentido, percebe-se que os diversos tipos de fluxo também são limitados por razões de natureza estritamente socioeconômica. Na Amazônia Legal, como em outras partes do País, é evidente a grande proporção de população que não possui bens materiais e educacionais suficientes para participar ativamente dos fluxos regionais e globais, sejam eles mercadorias, sejam eles serviços, sejam eles aqueles relacionados a demandas sociais hoje consideradas básicas, como acesso a bens e serviços modernos e mais sofisticados que deveriam estar disponíveis em cidades relativamente próximas, em uma rede urbana em pleno funcionamento.

Diante dessas considerações, podese afirmar com segurança que não existem condições adequadas para que os dois maiores centros da região, Manaus e Belém, consigam estruturar o território amazônico, ou seja, fazer de maneira suficiente e sa- tisfatória a intermediação entre os pequenos e os médios centros da Amazônia com o restante do País, ou até mesmo com as áreas que extrapolam o território nacional, na Pan-Amazônia ou no sistema mundial globalizado.

O estudo realizado pelo IBGE, "Regiões de Influência das cidades 2007”, apresenta alguns resultados interessantes que vão ao encontro do que foi afirmado no parágrafo anterior. Assim, foram identificadas 12 redes urbanas no Brasil de primeiro nível, comandadas pelas principais metrópoles. Manaus e Belém foram citadas como os dois principais centros estruturadores do território amazônico, comandando as redes que se estendem nessa porção do País. ${ }^{5}$

A Tabela 2 demonstra a dimensão das redes de primeiro nível delimitadas no estudo do IBGE (2008). Apenas as redes de São Paulo e Brasília apresentam áreas maiores do que as duas redes de primeiro nível da Amazônia. Vale lembrar que o tamanho territorial das redes amazônicas não é resultado de uma grande capacidade de articulação regional das maiores centralidades da Amazônia, mas sim, em razão das peculiaridades espaciais próprias da região. As redes de Manaus (1,71\%) e Belém (3,79\%) somam apenas $5,5 \%$ da população brasileira, o que faz com que essas redes tenham 
baixa densidade demográfica (2,15 e 5,53 hab. $/ \mathrm{km}^{2}$, respectivamente). Das 83 capitais regionais ${ }^{6}$ identificadas pelo IBGE, apenas quatro estão nas redes de Manaus (1) e Belém (3). Essas duas redes possuem 13 dos 199 centros sub-regionais, e apenas 14 dos 666 centros de zona brasileiros estão no raio de influência imediato das duas grandes cidades amazônicas. Apesar de a área de influência de São Luís (MA) não estar, de acordo com o IBGE (2008), entre as maiores redes do País, deve-se lembrar que São Luís aparece, em vários aspectos (de- mográfico, funcional, entre outros), em um patamar logo abaixo de Manaus e Belém.

O IBGE (2008) também disponibiliza uma variável chamada de "intensidade de relacionamento", que se refere ao número de vezes que as cidades de Manaus (554) e Belém (1.575) foram citadas no questionário do IBGE. Para se ter uma ideia, os valores da intensidade de relacionamento de São Paulo, Brasília, Rio de Janeiro e Belo Horizonte são, respectivamente, $12.857,2.908$, 3.124 e 8.520 . Todos os dados apontam para a situação de fragi-

Tabela 2_Dimensão das redes de primeiro nível

\begin{tabular}{|c|c|c|c|c|c|c|}
\hline \multirow{2}{*}{$\begin{array}{c}\text { Redes } \\
\text { de Primeiro } \\
\text { Nível }\end{array}$} & \multicolumn{6}{|c|}{ Dimensão } \\
\hline & $\begin{array}{l}\text { Capitais } \\
\text { regionais }\end{array}$ & $\begin{array}{l}\text { Centros sub- } \\
\text { regionais }\end{array}$ & $\begin{array}{l}\text { Centros } \\
\text { de zona }\end{array}$ & Municípios & População & $\begin{array}{l}\text { Área } \\
\left(\mathrm{km}^{2}\right)\end{array}$ \\
\hline São Paulo & 20 & 33 & 124 & 1028 & 51.020 .582 & $2.279 .108,45$ \\
\hline Rio de Janeiro & 5 & 15 & 25 & 264 & 20.750 .595 & $137.811,60$ \\
\hline Brasília & 4 & 10 & 44 & 298 & 9.680 .621 & $1.760 .733,86$ \\
\hline Fortaleza & 7 & 21 & 86 & 786 & 20.573 .035 & $792.410,65$ \\
\hline Recife & 8 & 18 & 54 & 666 & 18.875 .595 & $306.881,59$ \\
\hline Salvador & 6 & 16 & 41 & 486 & 16.335.288 & $589.229,74$ \\
\hline Belo Horizonte & 8 & 15 & 77 & 698 & 16.745 .821 & $483.729,84$ \\
\hline Curitiba & 9 & 28 & 67 & 666 & 16.178 .968 & $295.024,25$ \\
\hline Porto Alegre & 10 & 24 & 89 & 733 & 15.302 .496 & $349.316,91$ \\
\hline Goiânia & 2 & 6 & 45 & 363 & 6.408 .542 & $835.783,14$ \\
\hline Manaus & 1 & 2 & 4 & 72 & 3.480 .028 & $1.617 .427,98$ \\
\hline Belém & 3 & 11 & 10 & 161 & 7.686 .082 & $1.389 .659,23$ \\
\hline
\end{tabular}

Fonte: IBGE (2008a e 2008b), IBGE. Área territorial oficial. Rio de Janeiro, 2007.

Segundo o IBGE (2008), a capital regional possui capacidade de gestão imediatamente inferior ao da metrópole e tem área de influência regional, sendo referida como destino por um grande conjunto de municípios. O centro sub-regional possui atividades de gestão menos complexas e área de atuação mais reduzida. Seus relacionamentos externos à própria rede geralmente se dão com apenas três metrópoles nacionais. Já o centro de zona apresenta raio de atuação restrita a sua área imediata. 
lidade da rede urbana amazônica no que tange à capacidade de estruturação territorial, sobretudo no caso de Manaus, com intensidade de relacionamento menor do que cidades de porte médio como Juiz de Fora (1.268), Ribeirão Preto (853) e Montes Cla$\operatorname{ros}(845)$.

Manaus tem sua condição de articulador regional prejudicada pela localização desfavorável no interior da Amazônia e distante dos principais eixos rodoviários da região. Nesse caso, o posicionamento centralizado de Manaus na Amazônia cria diversos atritos para a centralidade dessa grande cidade na rede. Ou seja, mesmo diante da importância do transporte fluvial através do rio Amazonas, pode-se dizer que o coração da Amazônia está longe das principais veias e artérias que dinamizam os fluxos na região.

Em uma situação mais favorável, Belém, por sua vez, dado seu caráter locacional excêntrico, situada no extremo norte da Amazônia oriental, é também incapaz de cumprir o papel articulador da rede de cidades amazônicas que caberia a uma metrópole regional do seu porte.

Com base no estudo Cadastro Central das Empresas, pode-se calcular a intensidade de relacionamento empresarial dos dois maiores polos amazônicos. O IBGE (2008) define essa intensidade como "a soma do número de filiais existentes na cida- de $\mathrm{B}$ de empresas com sede na cidade $\mathrm{A}$ com o número de filiais existentes na cidade A de empresas com sede na cidade B'. Tais dados geraram uma série de informações valiosas que podem ser visualizadas na Tabela 3.

A primeira coisa que chama a atenção na Tabela 3 é que, de forma geral, Manaus apresenta intensidade de relacionamento empresarial superior a Belém, considerando as 20 ligações que mais se destacam. Vale lembrar que, como dito anteriormente, a intensidade de relacionamento de Manaus (554) com as demais cidades da rede é bem menor em relação ao que acontece na rede encabeçada por Belém (1.575). Tal situação pareceria improvável e incompatível com a realidade, não fosse o tamanho do PIB de Manaus ( $\mathrm{R} \$ 27.214 .213)$, mais do que o dobro do PIB de Belém (11.277.414), em 2005.

Os valores de intensidade de relacionamento empresarial de Belém e Manaus com as duas maiores metrópoles nacionais estão entre os mais altos do ranking da Tabela 3. Percebe-se que São Paulo e Rio de Janeiro superam até mesmo o relacionamento empresarial existente entre Belém e Manaus. Se por um lado isso evidencia a grande influência das grandes metrópoles do Sudeste na Amazônia, por outro reflete também a baixa integração regional entre Belém e Manaus. 
Tabela 3_Intensidade de Relacionamento Empresarial

\begin{tabular}{|c|c|c|c|c|c|c|}
\hline \multirow{2}{*}{ Ordem } & \multicolumn{3}{|c|}{ Belém } & \multicolumn{3}{|c|}{ Manaus } \\
\hline & Cidade & n & $\%$ & Cidade & n & $\%$ \\
\hline 1 & São Paulo (SP) & 360 & 23,53 & São Paulo (SP) & 602 & 37,23 \\
\hline 2 & Rio de Janeiro (RJ) & 150 & 9,80 & Rio de Janeiro (RJ) & 184 & 11,38 \\
\hline 3 & Manaus (AM) & 140 & 9,15 & Belém (PA) & 140 & 8,66 \\
\hline 4 & Macapá (AP) & 119 & 7,78 & Brasília (DF) & 104 & 6,43 \\
\hline 5 & Brasília (DF) & 115 & 7,52 & Porto Velho (RO) & 96 & 5,94 \\
\hline 6 & Fortaleza (CE) & 103 & 6,73 & Boa Vista (RR) & 64 & 3,96 \\
\hline 7 & São Luís (MA) & 83 & 5,42 & Recife (PE) & 49 & 3,03 \\
\hline 8 & Castanhal (PA) & 72 & 4,71 & Belo Horizonte (MG) & 48 & 2,97 \\
\hline 9 & Santarém (PA) & 50 & 3,27 & Fortaleza (CE) & 46 & 2,84 \\
\hline 10 & Marabá (PA) & 47 & 3,07 & Campinas (SP) & 38 & 2,35 \\
\hline 11 & Recife (PE) & 45 & 2,94 & Porto Alegre (RS) & 36 & 2,23 \\
\hline 12 & Curitiba (PR) & 40 & 2,61 & Cuiabá (MT) & 33 & 2,04 \\
\hline 13 & Belo Horizonte (MG) & 36 & 2,35 & Curitiba (PR) & 33 & 2,04 \\
\hline 14 & Altamira (PA) & 30 & 1,96 & Macapá (AP) & 32 & 1,98 \\
\hline 15 & Abaetetuba (PA) & 28 & 1,83 & Rio Branco (AC) & 25 & 1,55 \\
\hline 16 & Goiânia (GO) & 24 & 1,57 & Itacoatiara (AM) & 20 & 1,24 \\
\hline 17 & Capanema (PA) & 23 & 1,50 & Salvador $(\mathrm{BA})$ & 18 & 1,11 \\
\hline 18 & Santa Isabel do Pará (PA) & 22 & 1,44 & Goiânia (GO) & 17 & 1,05 \\
\hline 19 & Paragominas (PA) & 22 & 1,44 & Manacapuru (AM) & 16 & 0,99 \\
\hline 20 & Breves $(\mathrm{PA})$ & 21 & 1,37 & São Luis (MA) & 16 & 0,99 \\
\hline Total & & 1530 & 100 & & 1617 & 100 \\
\hline
\end{tabular}

Fonte: IBGE. Cadastro Central de Empresas, 2004; IBGE (2008b). 
A intensidade empresarial de Belém com o restante do Estado do Pará (20,58\%) evidencia maior equilíbrio em relação ao que ocorre no Estado vizinho. No Amazonas, Manaus possui intensidade de relacionamento empresarial de apenas 2,22\% com as demais cidades do Estado citadas na Tabela 3. Todas as outras cidades mencionadas estão fora do Amazonas, e quatro são do Sudeste brasileiro.

Já a Tabela 4 e a Figura 3 do Anexo apresentam o resultado de uma matriz de funcionalidades que elaboramos para todos os municípios da Amazônia Legal com população superior a 20.000 habitantes em 2007. Na Tabela 4, verifica-se apenas os 98 municípios com maior diversificação funcional na Amazônia Legal. A Figura 3 do Anexo apresenta os dados para todos os municípios trabalhados. As funções escolhidas buscaram abranger desde atividades mais simples, a exemplo de escolas de ensino médio e fundamental, até as mais sofisticadas, como escolas de nível superior e a disponibilidade de cursos de pós-graduação com conceito 6 ou 7 avaliados pela Capes.

Como pode ser observado na Tabela 4 , os sete primeiros municípios no ranking são capitais estaduais. A primeira cidade do interior (não capital) da Amazônia Legal é Imperatriz (MA), com 83,56\% (61) do total das 73 funções pesquisadas. De todos os municípios pesquisados (243), per- cebe-se que 77 eram dotados de mais de $50 \%$ das funções e apenas 10 possuíam mais de $80 \%$, sendo todos eles sedes de capitais estaduais, com exceção de Imperatriz e Ji-Paraná.

Se Manaus e Belém possuem população bem superior à das demais cidades da rede, percebe-se que, no que diz respeito à disponibilidade de funções, cidades de porte inferior podem exibir um nível de centralidade comparável aos dois maiores centros articuladores das redes amazônicas.

De maneira mais completa, a Figura 3 do Anexo apresenta o nível de diversificação funcional dos municípios com mais de 20.000 habitantes na Amazônia Legal (\% em relação ao total de 73 funções). Parece claro que a maior concentração desses municípios se dá na porção oriental da Amazônia Legal, sobretudo, nas intermediações de Belém e São Luís. Na porção ocidental, os municípios representados são mais dispersos e, geralmente, não possuem proporção elevada de funções.

Ademais, em uma rede urbana dinâmica e equilibrada, os centros de porte médio e pequeno assumem papéis importantes que devem ser levados em consideração. A proliferação desses municípios na Amazônia Legal lançou vários desafios para os formuladores e os gestores de políticas públicas. 
Tabela 4_Funcionalidades (73, no total) dos municípios da Amazônia Legal ( + 20.000 hab. em 2007)

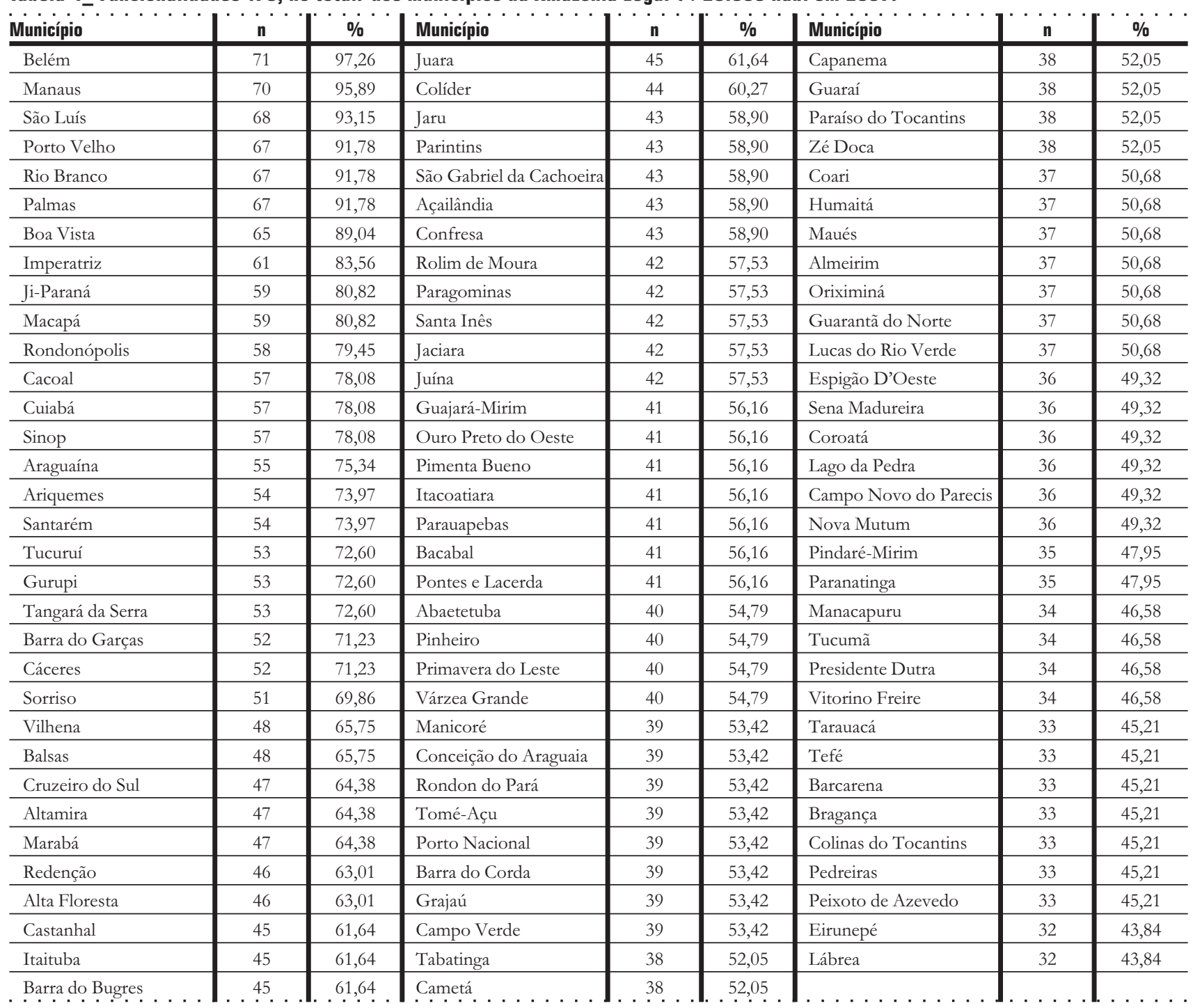

Fonte: Elaboração própria a partir dos dados do IBGE, Censo demográfico (2000 e 2007), Atlas de desenvolvimento Humano do Brasil (2000), INEP (2006), Banco Central (2004), Estatíticas de Saúde do IBGE (2000), Perfil dos Municípios - Cultura (2006). 
רer Amotim Fiho (1976)

7 Ver Amorim Filho (1976) e também o relatório da União Internacional dos Arquitetos (1999).

8 A expressão "médio porte" está relacionada apenas ao limiar demográfico, enquanto que a "cidade média" incorpora uma série de outros elementos. Nesse sentido, um município de médio porte pode ou não ser considerado uma cidade média.
No que se refere ao aparente surto de "cidades médias" na Amazônia Legal, deve ficar claro que esses centros de porte intermediário muitas vezes não satisfazem a complexidade conceitual contida nesse termo. A cidade média se define, de acordo com Lajugie (1974), antes de tudo, por suas funções, pela posição que ocupa na rede urbana, entre a metrópole, com vocação regional, e os pequenos municípios, com influência puramente local (Amorim Filho e Rigotti, 2002). As cidades médias, além de ter tamanho demográfico para esse porte, desempenham papéis funcionais intermediários bem definidos entre a(s) metrópole(s) e as cidades pequenas que compõem uma rede urbana (Sposito, 2004).

Algumas das características citadas pelos teóricos ${ }^{7}$ como indispensáveis às cidades médias não são encontradas, ou existem de maneira incipiente, nos municípios de médio porte ${ }^{8}$ da Amazônia Legal, o que cria desafios a ser transpostos na definição dos parâmetros adequados para selecionar as cidades médias dessa região. Diante da nítida importância dos aspectos funcionais e do componente espacial, percebe-se que, no caso amazônico, critérios estritamente demográficos podem não ser capazes de estabelecer classificação adequada dos níveis hierárquicos urbanos. Sendo assim, muitas das cidades tidas como médias por apre- sentarem expressivo contingente populacional, na verdade não são médias no sentido funcional, por sofrerem com as condições adversas para o desenvolvimento de seu papel de intermediador de fluxos, ao contrário do que se observa em uma rede urbana em perfeito funcionamento.

Estudos e reportagens têm frequentemente divulgado as melhores condições de vida desfrutadas pelos habitantes das cidades médias do Sudeste do País, que oferecem uma série de amenidades urbanas, a saber: menores índices de criminalidade, tempo e gasto reduzidos no trânsito, menores níveis de poluição, custos de moradia e transporte mais acessíveis e maior proximidade com áreas verdes (Amorim Filho e Serra, 2001).

Entretanto, Sathler et al. (2007) sugerem que, diferentemente das cidades médias do Centro-Sul do País, que oferecem novas possibilidades de trabalho e melhoria das condições de vida para a população, na Amazônia Legal os municípios do interior, com população entre 100.000 e 500.000 habitantes, refletem predominantemente desemprego e pobreza. Os autores verificaram que Belém, Manaus e as demais capitais estaduais da Amazônia Legal oferecem, de maneira geral, melhores condições de vida em relação aos municípios do interior com população entre 100.000 e 500.000 habi- 
tantes no ano de 2000 , realidade oposta à das regiões que compõem o centro dinâmico da economia brasileira.

Além disso, pode-se observar certas tendências não presentes nas décadas anteriores, que apontam para a existência de uma dinâmica diferenciada nas redes de cidades da Amazônia Legal. As cidades médias amazônicas aparecem hoje como novos vetores de crescimento econômico e demográfico sem, no entanto, afetar a primazia das Regiões Metropolitanas de Belém (RMB) e de Manaus.

Deve-se ressaltar também que, diferentemente do que ocorre nas redes de cidades do Centro-Sul do País, as referidas enormes distâncias dos municípios de médio porte em relação às metrópoles regionais e às capitais estaduais, assim como suas evidentes carências de infraestrutura, criam uma situação de isolamento, que, em tese, exigiria que os municípios de médio porte oferecessem uma série de serviços que não seriam necessários ou compatíveis nas cidades médias de uma região dotada de uma rede urbana bem articulada. Entretanto, muitas vezes a fragilidade da demanda efetiva local e regional, marcada por populações de baixa renda e pequena capacidade produtiva, exige que os habitantes dessas cidades percorram grandes distâncias à procura de serviços, presentes somente em municí- pios pertencentes a níveis hierárquicos superiores nas redes de cidades amazônicas.

Assim, considerando as especificidades das redes urbanas amazônicas, percebe-se que algumas localidades que, na escala nacional, apresentam porte demográfico intermediário acabam por ter a responsabilidade de ser o destino final na procura de serviços para a maior parte da população. Esse desequilíbrio, de difícil solução, impõe a esses centros de porte intermediário maior leque de demandas sociais, ao contrario do que acontece com centros do mesmo porte em uma rede urbana equilibrada. Diante disso, cabe aos formuladores e aos gestores perceberem essas peculiaridades espaciais no momento de organizar a oferta de serviços públicos nessa região, sobretudo aqueles de natureza básica.

Já no que diz respeito à proliferação de centros locais nas redes urbanas da Amazônia Legal, deve-se ter em mente que, mesmo diante de todas as dificuldades existentes relativas à fluidez, essa proliferação responde a uma tendência nacional: os centros locais estão mais urbanizados e mais integrados do que se observava havia décadas. Sob essa perspectiva, pode-se inferir que existe no Brasil, atualmente, maior integração desses pequenos municípios com os demais centros urbanos inseridos na rede, assim como maior participação desses 
como nós dos diversos fluxos materiais e imateriais. Sendo assim, para entender a maior inserção desses pequenos municípios na rede de cidades, deve-se não apenas olhar para as mudanças que estão ocorrendo fora desses lugares, mas também perceber as transformações que estão ocorrendo no interior desses pequenos centros locais.

No Brasil, e em menor medida na Amazônia Legal, diante dos altos níveis de precariedade nos centros locais da região, esse aumento da urbanidade que, anteriormente, tinha sua economia menos diversificada e apoiada quase que exclusivamente nas atividades ligadas à terra está relacionado a um conjunto de fatores, entre eles:

a. melhoria no nível geral das condições de vida e diminuição da pobreza;

b. maior acesso à informação e a sensação de que as distâncias são menores do que no passado;

c. melhoria na infraestrutura regional e intramunicipal;

d. maior integração dos moradores com pessoas que residem em municípios médios ou grandes, a exemplo de parentes, amigos ou mesmo quando se trata do caso de migrantes retornados.

Ao final, nas últimas décadas, as grandes transformações urbanas no interi- or da Amazônia estiveram muito sujeitas a decisões quase sempre distantes, que partiam dos grandes centros urbanos regionais (Belém e Manaus), de Brasília, São Paulo e mesmo de outras partes do mundo. As "redes de gestão" na Amazônia se parecem muito com as antigas redes dendríticas, diante da alta centralização do poder político. Nesse sentido, muitos municípios de pequeno e médio portes funcionavam como vetores para a exploração predatória dos recursos, sem a preocupação por parte do poder público e da iniciativa privada em criar polos de desenvolvimento econômico no interior da região.

\section{5_Considerações finais}

Todos os argumentos discutidos nos tópicos anteriores poderiam levar a pensar em uma única questão: existe uma rede amazônica de cidades? Ou haveria que se pensar em uma série de questões, implicando a existência de diversas redes de cidades na região, não necessariamente articuladas entre si ou mesmo articuladas internamente de forma simplificada? É possível pensar em amplas redes de cidades hierarquicamente articuladas a partir apenas dos dois grandes polos regionais, Belém e Manaus? Ou seria necessário pensar também em uma ou mais redes de 
cidades articuladas a partir do grande vetor de transformação da Amazônia contemporânea, ou seja, o "arco rodoviário" que redefiniu sua ocupação nas últimas décadas e marcou sua integração com o resto do País?

A resposta a esse conjunto de questões não é de forma alguma simples, mas pode-se dizer que pensar em uma única rede urbana amazônica, em toda a complexidade que caracteriza uma rede madura e equilibrada, parece impossível. De fato, como discutido acima, sob a ótica das demandas sociais imediatas, não existem condições materiais e imateriais para que os diversos tipos de fluxo integrem a região de maneira adequada. Mergulhando mais profundamente nessa questão, pode-se inferir que o eventual sonho de vários planejadores de uma Amazônia integrada talvez nunca se concretize, diante de suas peculiaridades espaciais e, até mesmo, naturais. $\mathrm{E}$ é possível que seja melhor assim, o que favorece a diversidade que caracteriza essa região, maior que o resto do Brasil, e que vem correndo riscos de diversas naturezas que a ela atingem valendo-se de decisões distantes, externas aos interesses da própria região e, muitas vezes, externas aos próprios interesses nacionais.

Já no que tange especificamente aos fluxos materiais, não é absurdo dizer que a
Amazônia se apresenta cada vez mais como uma grande rede integrada. Nessa perspectiva, o eixo principal seria o rio Amazonas, que liga os dois maiores centros econômicos da região, além das grandes rodovias que cortam a Amazônia e ajudam na integração com os grandes polos nacionais (Brasília e São Paulo), de onde emanam as principais decisões que afetam a ocupação e a estruturação na Amazônia.

Existem outros aspectos importantes que dão coesão interna às centenas de territorialidades amazônicas. Nesse sentido, pode-se supor que, em alguma medida, esses aspectos estariam relacionados aos costumes e às atividades culturais. Qual o papel da "identidade amazônica", que simplificadamente pode ser entendida como a "cultura da floresta", presente inclusive nos grandes centros urbanos? Apesar da carência de dados empíricos que confirmem essa hipótese, a rede cultural amazônica talvez possa estimular maior relacionamento até mesmo entre centros distantes, onde determinados tipos de fluxo podem estar se direcionando para áreas dentro da Amazônia, por razões que superam os estímulos de ordem puramente econômica.

Baseando-se nas considerações dos parágrafos anteriores, percebe-se que uma abordagem sensata deve levar em consideração que os diversos tipos de fluxo se 9 Nesse aspecto, pode-se citar vários fatores importantes, a saber: os hábitos alimentares; a expressão artística e musical; o relacionamento das pessoas com os rios, presente e importante em várias cidades amazônicas; os mitos e os elementos culturais populares, regionais e locais; entre vários outros. 
10 Miossec (1976) considerava três tipos de interações espaciais geradoras de redes: a distribuição (difusão), a produção e gestão (decisão). Ao retomar a metodologia de Miossec (1976), Ribeiro (1998) declara que "estas redes apresentam-se superpostas, indicando a complexidade das interações espaciais". comportam de maneira diferenciada no espaço. As fontes geradoras e receptoras, o alcance, o direcionamento e a intensidade dos fluxos são fatores que estão relacionados, em grande medida, com a natureza dos próprios fluxos. Sendo assim, uma boa forma de imaginar o mundo das redes seria através da ideia dos "layers", ou seja, separando os fluxos em camadas distintas que, quando sobrepostas, formam a realidade em toda sua complexidade. ${ }^{10}$

Ademais, cabe ressaltar que as falhas de integração territorial são evidentes, inclusive no interior das UFs amazônicas, a exemplo dos conflitos de natureza política que ocorrem nos dois maiores Estados da região. No Pará, as dificuldades de gestão e de relacionamento político-administrativo das autoridades estaduais centradas em Belém, capital excêntrica e distante, com as áreas interioranas no restante da UF se refletem na limitação das demais regiões do Estado em obter investimentos e recursos, o que tem estimulado o aparecimento de movimentos emancipatórios, como os da criação dos Estados do Tapajós e do Carajás. Já no caso do Amazonas, a própria situação de macrocefalia urbana de Manaus, por si só, implica alta concentração do poder político.

Parece claro que as vantagens econômicas e logísticas advindas da distribui- ção organizada e integrada dos centros urbanos fazem com que as cidades em rede sejam muito mais do que a soma das partes (Meijers, 2005). Esse é o pensamento que deveria estar presente em todas as políticas de desenvolvimento regional cogitadas para a Amazônia brasileira. 


\section{Referências bibliográficas}

\section{AMORIM FILHO, O. B. Um} esquema metodológico para o estudo das cidades médias In: ENCONTRO NACIONAL DE GEÓGRAFOS, 2., 1976, Belo Horizonte. Anais... Belo Horizonte: IGC, UFMG, 1976.

AMORIM FILHO, O. B.; SERRA, R. V. Evolução e perspectivas do papel das cidades médias no planejamento urbano e regional. In: ANDRADE, T. A., SERRA, R. V. (Org.). Cidades médias brasileiras. Rio de Janeiro: IPEA, 2001.

AMORIM FILHO, O. B.; RIGOTTI, J. I. R. Os limiares demográficos na caracterização das cidades médias. In: Encontro Nacional de Estudos

Populacionais, 13., 2002. Caxambu. Anais... Caxambu: ABEP, v. 1, 2002.

BECKER, B. Amazônia. São Paulo: Ática, 1990.

BECKER, Bertha K. Síntese do processo de ocupação da Amazônia: lições do passado e desafios do presente. In: Causas da dinâmica do desmatamento do Amazônia. Brasília, MMA, 2001.

CASTELLS, Manuel. A sociedade em rede. São Paulo: Paz e

Terra, 1999
CURIEN, Nicolas. "D'une problématique générale dês réseaux à l'analyse économique du transport dês informations". In: DUPUY, Gabriel (Ed.). Réseaux Territoriaux.. Caen: Ed. Paradigme, 1988.

IBGE. Instituto Brasileiro de Geografia e Estatística. Censo demográfico 1970. Rio de Janeiro: IBGE, 1971

IBGE. Instituto Brasileiro de Geografia e Estatística. Censo demográfico 1991. Rio de Janeiro: IBGE, 1972

IBGE. Instituto Brasileiro de Geografia e Estatística. Censo demográfico 1980. Rio de Janeiro: IBGE, 1981

IBGE. Instituto Brasileiro de Geografia e Estatística. Censo demográfico 2000. Rio de Janeiro: IBGE, 2001

IBGE. Instituto Brasileiro de Geografia e Estatística. Comunicação social. Rio de Janeiro: IBGE, 2007. Disponível em: $<$ http://www.ibge.gov.br/ home/presidencia/noticias/notici a_visualiza.php?id_noti $c i a=799>$. Acesso em: 13 dez. 2008

IBGE. Instituto Brasileiro de Geografia e Estatística. Contagem da populacãa 2007. Rio de Janeiro: IBGE, 2008a.
IBGE. Instituto Brasileiro de Geografia e Estatística. Regiões de influência das cidades 2007. Rio de Janeiro: IBGE, 2008b.

LAJUGIE, J. Les Villes Moyennes. Paris: Éditions Cujas, 1974.

MATOS, R. Espacialidades em rede População, urbanização e migração no Brasil contemporâneo. Belo Horizonte: Editora, 2005.

MEIJERS, E. Polycentric Urban regions and the quest for synergy: is a network of the cities more than the sum of the parts? Urban Studies, v. 42, n. 4, p. 765-781, April 2005.

MIOSSEC, J. M. La localisation des forces de décision dans le monde: equisse de géographie politique théorique. L'espace géographique, Paris, v. 3, n. 2 , p.165-175, Jul. 1976

MONTE-MÓR, Roberto L. Urbanização extensiva e novas lógicas de povoamento: um olhar ambiental. In: SANTOS, Milton $e$ al. Território: globalização e fragmentação. São Paulo: Hucitec/Anpur, 1994. p. 169-181.

ROBERTSON, Roland. Globalization: Social Theory and Global Culture. London: Sage, 1992.

SANTOS, MILTON. O trabalho do geógrafo no Terceiro Mundo. São Paulo: Hucitec, 1978.
SANTOS, Milton. Técnica, espaço, tempo: globalização e meio técnico-científico informacional. São Paulo: Hucitec, 1994

SANTOS, Milton. A natureza do espaço. São Paulo: Hucitec, 1997.

SATHLER, D.; FELIPPE, M.; RIBEIRO, E. 2007. As cidades médias da Amazônia Legal: uma análise comparativa dos aspectos demográficos e socioeconômicos In: Encontro Nacional da ANPUR, 12., 2007. Belém. Anais... Belém: Anpur. v. 1.

SOJA, Edward W. Postmetropolis: Critical studies of cities and regions. Malden: Blackwell Publishing, 2000

SOUZA, Carlos Augusto de Silva Urbanização na Amazônia. Belém do Pará: Unama, 2000.

SPOSITO, Maria Encarnação Beltrão. O chão em pedaços: urbanização, economia e cidades no Estado de São Paulo. 2004. 508 p. Tese (Livre Docência em Geografia) - Faculdade de Ciências e Tecnologia, USP Presidente Prudente, 2004.

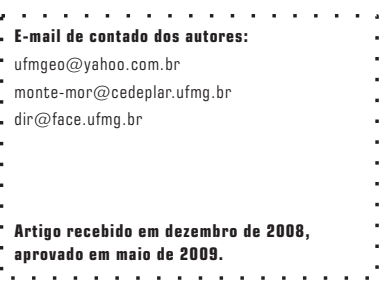


Anexo

Figura 1_Evolução do tamanho populacional na Amazônia Legal (1970-2000)*
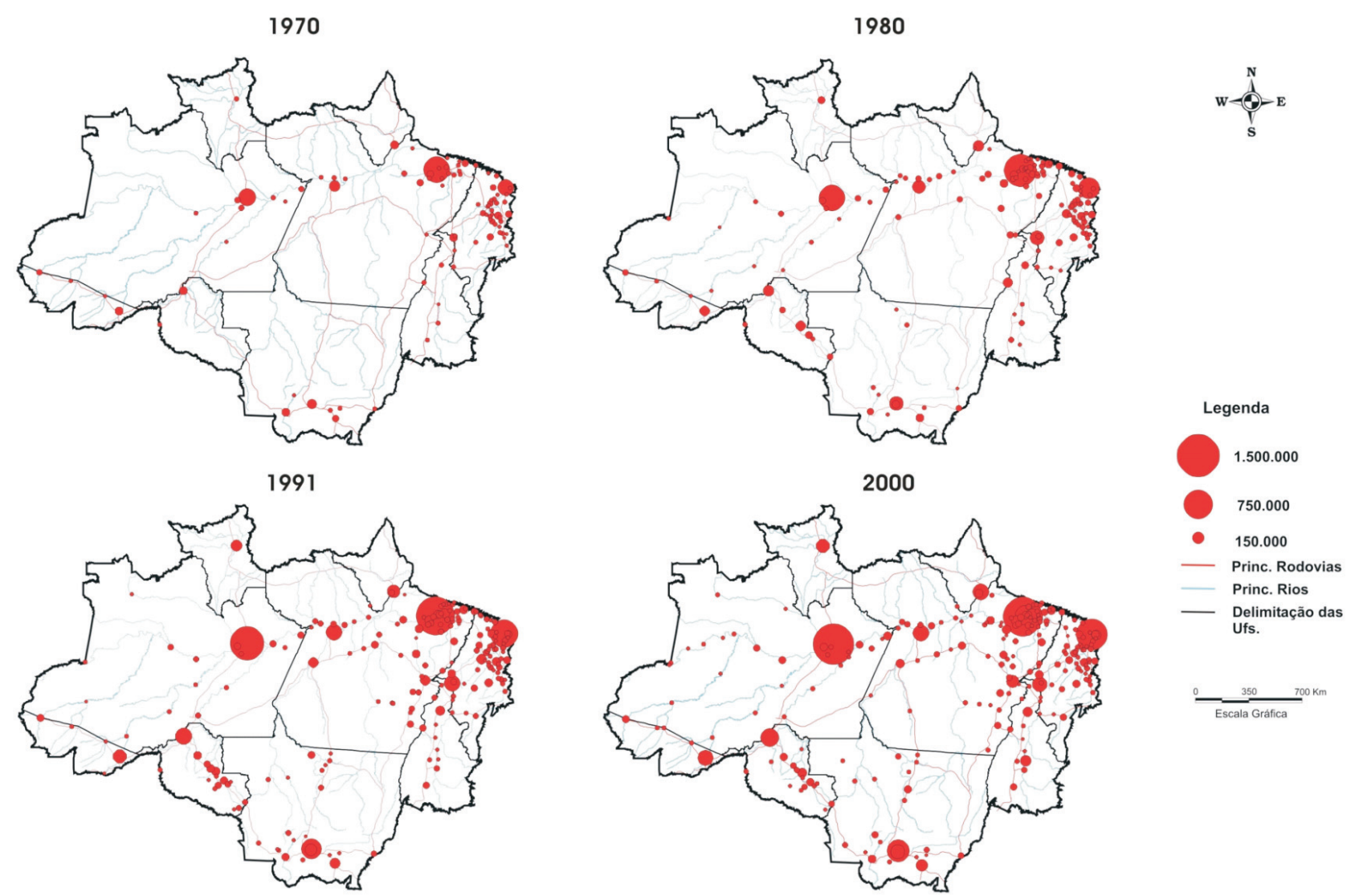

Fonte: Censos Demográficos (1970-2000).

Elaboração: Douglas Sathler

Projeção: Lat.xLong.SAD69

* População dos municípios com mais de 20.000 hab. Os demais municípios não estão representados. 
Figura 2_ População da Amazônia Legal (2007)*
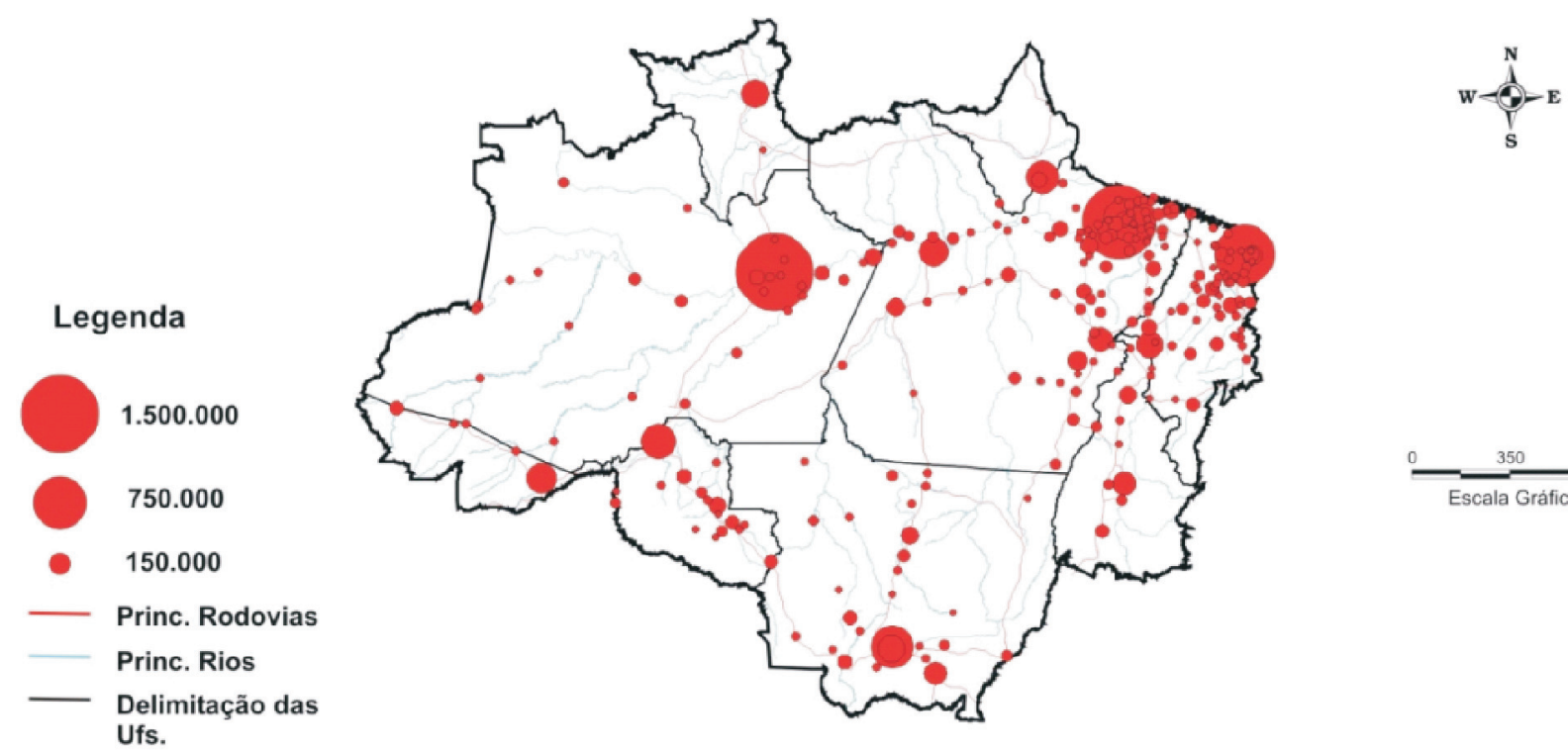

Fonte: Contagem (2007).

Estimativas: IBGE (2007).

Elaboração: Douglas Sathler

Projeção: Lat.xLong.SAD69

* População dos municípios com mais de 20.000 hab. Os demais municípios não estão representados. 


\section{Figura 3_ Nível de Diversificação Funcional na Amazônia Legal*}

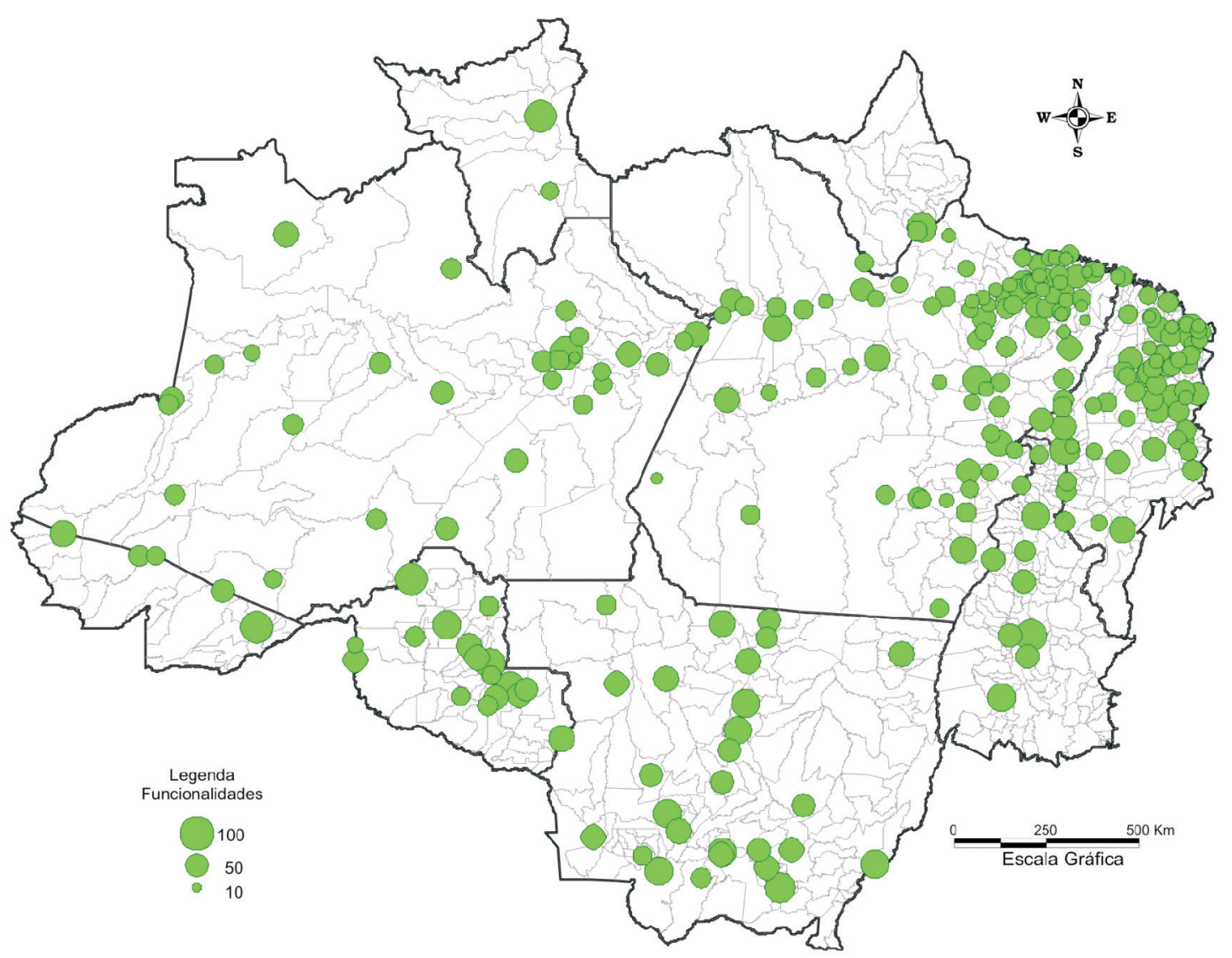

Fonte: Elaboração própria a partir do dados do IBGE. Censo demográfico (2000 e 2007), Atlas de desenvolvimento Humano do Brasil (2000), INEP (2006), Banco Central (2004), Estatísticas de Saúde do IBGE (2000). IBGE. Perfil dos Municípios - Cultura (2006).

Elaboração: Douglas Sathler

Projeção: SAD69 Latitude x Longitude

* Apenas municípios com mais de 20.000 hab. 
Figura 4_Capitais estaduais e municípios de médio porte da Amazônia Legal, 2007
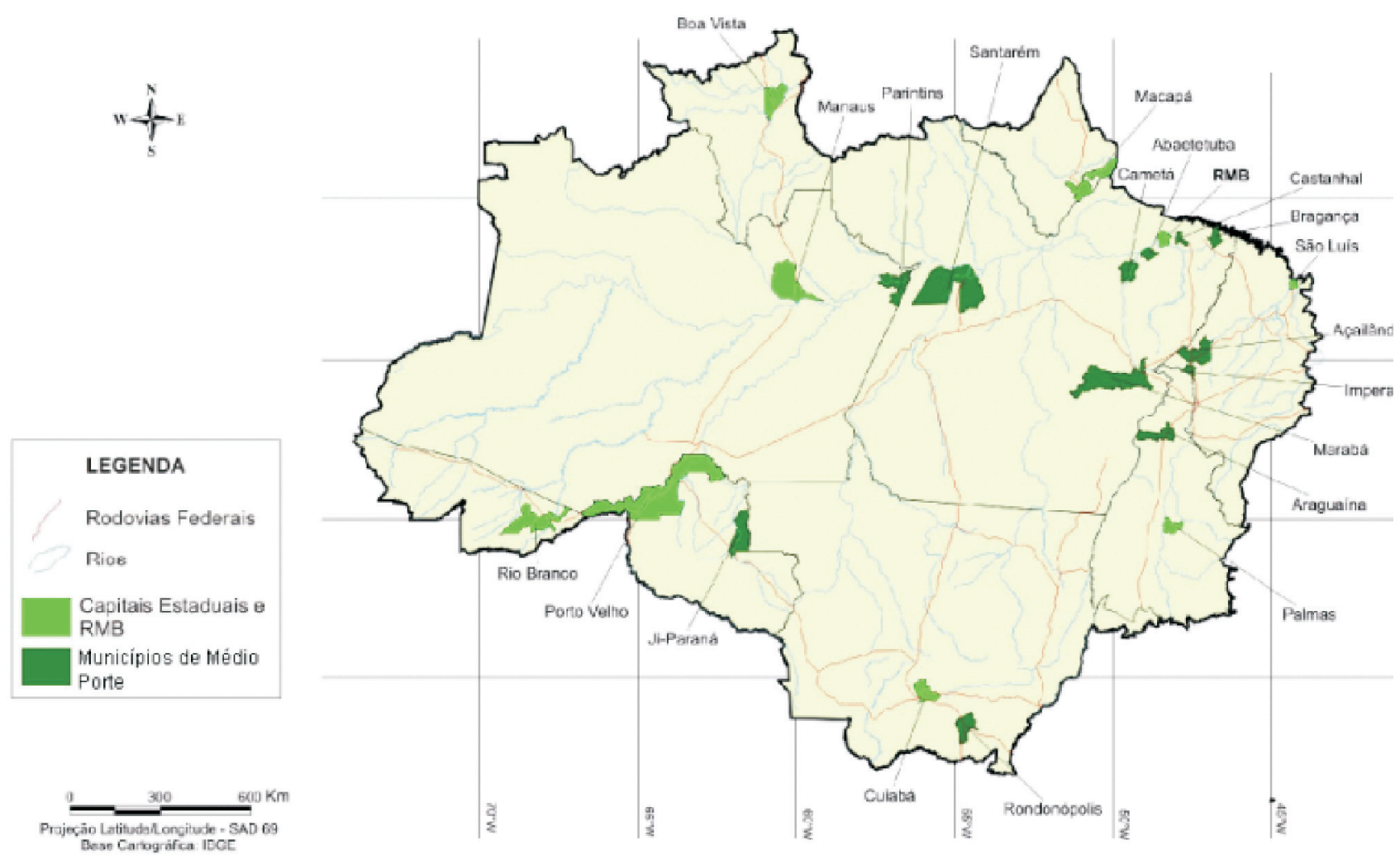

Fonte: Base Cartográfica do IBGE. IBGE. Contagem da população (2007). 